\title{
Formation and Development of the Ecosystem of Innovative Education in the Region
}

\author{
Kseniya A. Elistratova 1*[ORCID 0000-0002-4955-2784], \\ Irina A. Donina 2[ORCID 0000-0002-8191-196X], \\ Tatyana G. Ryboretskaya 3[ORCID 0000-0003-3993-7434]
}

\author{
${ }^{1}$ School of General Secondary Education “Murinsky Education Center No. 4”, Murino, Leningrad Region, \\ Russia \\ ${ }^{2}$ Yaroslav-the-Wise Novgorod State University, Veliky Novgorod, Russia \\ ${ }^{3}$ Committee for General and Vocational Education of the Leningrad Region, Saint Petersburg, Russia \\ xenos88@mail.ru
}

\begin{abstract}
The article actualizes and discusses the formation and development of the ecosystem of innovative education in the region, an attempt is made to substantiate such an ecosystem. The purpose of the study, the results of which are presented in the article, was to substantiate the methodology of the ecosystem approach in relation to the consideration of innovative education systems, the analysis of internal and external factors that influence innovation processes. The article notes that in the ecosystem of innovative education in the region, its subjects actively interact with any other subject in their joint innovation activities. The ecosystem of innovative education in the region is interpreted and refers to an integrated environment where all subjects (managers, teachers, methodologists, specialists in the field of IT-technologies, students, representatives of science) interact with each other, as well as with a variety of innovative products, technologies, methods learning and other elements of the educational ecosystem. Moreover, instead of exchanging energy between components (as is customary in natural ecosystems), information is exchanged in an educational ecosystem, especially an innovative one. In the logic of the ecosystem approach, innovative models of the cross-multidimensional organization of the educational process are proposed, when the educational environment is complemented, intersected and interacts with other spaces and environments that have an appropriate educational and developmental potential. The article presents and discusses the results of a study with the participation of forty-six managerial and pedagogical workers, aimed at identifying effective managerial and pedagogical practices to stimulate and implement the innovative activity of the subjects of the educational process. Also presented is information obtained using the Ishikawa causal diagram on a set of factors that restrain the participation of teachers in innovative activities, limiting their innovative activity.
\end{abstract}

Keywords: regional system of education; innovative activity; innovative practices; ecosystem of innovative education in the region

\section{INTRODUCTION}

The development of modern education, educational systems is characterized by innovation, focus on renewal, quality improvement and competitiveness.

At the state level, a number of decisions have been made that determine educational policy for the foreseeable future. Among such solutions:
- digital transformation, the use of digital tools in the management of educational institutions, the educational process, in expanding the accessibility of students to modern digital resources, in the implementation of career guidance work with students;

- qualitative renewal of the staff of management and teaching staff, the use of 
new mechanisms for improving their qualifications, certification, diversification of forms and technologies for advanced training, giving this process a continuous nature;

- updating the content of education, modernizing subject areas, focusing on new educational results, including functional literacy, soft skills, cross-cutting competencies;

- development, renewal of educational infrastructure, creation in the regions of a network of innovative structures in the form of Centers for Continuous Professional Development of Teachers, Quantoriums, ITcubes, "Growth Points", Centers for working with gifted children, etc.

All of this, ultimately, is aimed at improving the quality of education, educational results, and achieving the competitiveness of Russian school education at the global level.

Digital transformation in school education around the world determines the future roadmap of innovative education management strategies [1-5].

At the same time, the analysis of decisions, programs, projects adopted and implemented at the federal level $[6,7]$ shows that there are certain risks of failure to achieve, failure to fulfill the stated goals. This is due not only and not so much to the limited financial resources, a certain inertia of the education system, the unpreparedness of managers and teachers for changes, but rather to the insufficient elaboration of the methodological and conceptual foundations of these changes, the pace and sequence of their implementation.

Taking into account the above, it seems legitimate to distinguish such a problem as the substantiation of the ecosystem of innovative education in the region for consideration.

\section{MATERIALS AND METHODS}

The aim of the study is to determine the possibilities and directions of using the ecosystem approach in relation to the management of innovative processes in the regional education system. The research objectives follow from the above goal and can be formulated as: 1) development of methodological and conceptual foundations for the development of an ecosystem of innovative education in the region; 2) determination of priorities, "points of growth" of the ecosystem of innovative education in the region; 3 ) substantiation of models, selection of effective managerial and pedagogical practices for stimulating and implementing innovative activity of subjects of the educational process.

To implement the set goals and objectives, the methodological apparatus was used in the form of quantitative and qualitative methods (analysis of regulatory documents, scientific sources; study and analysis of statistical data; Ishikawa's causal diagram; online survey of respondents from among management personnel, teaching staff; methods and techniques statistical processing of empirical data.

\section{RESULTS}

Innovative activity in the regional educational system covers many areas and is carried out at various organizational levels. At the same time, its main goal is to update the content, forms, methods and technologies of educational activities.

With regard to innovative education, with good reason, it can be argued that when building a management system for it, studying and analyzing it, one can speak of it as a certain ecosystem.

The ecosystem approach has recently gained significant acceptance as a methodology for considering complex systems. Its feature is the use and transfer of laws, principles, models of living nature, biological systems to social, ergatic systems [8].

The ecosystem is an open system and is characterized by input and output flows of matter and energy [9]. From the point of view of information technology, an ecosystem means the interconnection of all services of an educational organization, a regional education system with each other. Each of them, especially in order to expand the field of innovation, seeks to create its own ecosystem and attract the largest number of teachers and managers into it [10].

In connection with the rapid development of information technologies and systems in education, the widespread use of digital educational resources, a radical rethinking of the learning process itself is taking place, new concepts and paradigms of education are being developed.

In any ecosystem (in the regional education system as well), its subjects interact with any other subject in their joint innovative educational environment. In accordance with this provision, the ecosystem of innovative education refers to an integrated environment where all subjects (managers, teachers, methodologists, IT-specialists, 
students, representatives of science) interact with each other, as well as with a variety of innovative products, technologies, learning methods and other elements of the educational ecosystem. Moreover, instead of exchanging energy between components (as is customary in natural ecosystems), information is exchanged in an educational ecosystem, especially an innovative one.

The educational ecosystem facilitates cooperation between the subjects of innovation and is an ideal environment for the implementation of new approaches, models, paradigms, learning and education technologies through the effective use of information technologies, systems and resources [10].

The key conditions for the successful development of such an ecosystem of innovative education according to the Edutech company, which is a leader in the development of learning ecosystems, include:

- project-based training, which allows managers and teachers to acquire the skills necessary in the 21 st century in the context of real-life projects (in this case, a team approach is also possible);

- integration of various sources of information, the ability to work with external resources in relation to solving innovative problems;

- introduction of the latest technologies to satisfy the information needs of the subjects of innovation.

The main components of the innovation ecosystem of education are a variety of Internet learning technologies, interactive learning tools, repositories of digital resources. At the same time, Internet technologies are fundamental.

The most fruitful and promising postulates of the ecosystem approach in relation to the study and analysis of innovative processes in the regional education system are those that explain the movement and exchange of energy, information, the conditions for the systems to maintain their internal balance, balance with the external environment.

Methodologically, in relation to education in the region, this can be expressed in the fact that the ongoing innovative changes, of course, give new energy of changes, lead to the emergence of new communication channels, new practices, require significant efforts to provide them with resources, change the very inter-system and exterosystem balance.

It is important to note the factor of significant complication of educational systems and their management. As an example of the complication of educational systems, we can give an example with the cross-multidimensional organization of the educational process at school, when teachers in the process of educational activity rely on, use the potential and capabilities of various spaces and environments (digital, library and media, historical and cultural, architectural, geographical environment, semantic, axiological space).

Among the innovative models of the crossmultidimensional organization of the educational process, one can single out models focused on expanding the information environment of educational activities; models on the basis of which the values and achievements of the types and kinds of cultures of human activity are transmitted; models that make it possible to update and diversify educational practices, to strengthen the activity component of the educational process.

Using the Ishikawa causal diagram ("fish skeleton" diagram), we identified a complex of factors that hinder the participation of teachers in innovative activities, limiting their innovative activity

In total, four large groups of reasons for the first level have been identified: management of innovative activities; resource provision of innovative activity; legal support of innovative activities; scientific, methodological and informational support of innovative activities.

Among the most cited reasons for the second level are the following:

- imperfection of the mechanisms for stimulating the teacher's innovative activity;

- undeveloped forms of network interaction of subjects of innovation in the region;

- lack of a unified policy and system for managing the quality of innovation;

- lack of effective mechanisms for the transfer of innovations, support for the expanded use of innovations in the post-testing period.

An online survey conducted with the participation of forty-six managerial and pedagogical staff made it possible to identify effective managerial and pedagogical practices for stimulating and implementing innovative activity of the subjects of the educational process. Table 1 presents a list of eight such practices that received 25 percent or more of the elections in the course of the poll. 
Table 1. Results of an online survey of management and teaching staff on the identification of effective management and pedagogical practices to stimulate and implement innovative activity of subjects of the educational process

\begin{tabular}{|c|lc|}
\hline No. & \multicolumn{1}{|c|}{ Estimated Positions } & $\begin{array}{c}\text { Frequency of } \\
\text { Mention (\%) }\end{array}$ \\
\hline 1 & Creation and functioning of interschool collaborations to solve individual innovative problems & 34.8 \\
\hline 2 & $\begin{array}{l}\text { Conducting regional (municipal) foresight sessions for management and teaching staff on topical } \\
\text { areas of innovation }\end{array}$ & 50.2 \\
\hline 3 & Transfer of innovations inside and outside the educational system & 60.3 \\
\hline 4 & Access to full versions of descriptions of completed innovative projects & 45.3 \\
\hline 5 & Creation of temporary structures for solving certain innovative problems & 28.6 \\
\hline 6 & Application of predictive models in relation to venture innovation projects & 30.8 \\
\hline 7 & Assessment and monitoring of the level and quality of innovation (indices, ratings, etc.) & 58.9 \\
\hline 8 & Research on the quality of the innovation environment, innovation activity & 5 \\
\hline
\end{tabular}

Source: Compiled by the authors based on the survey results

As follows from Table 1, most of the effective managerial and pedagogical practices for stimulating and implementing the innovative activity of the subjects of the educational process are associated with management processes. Among the pedagogical practices named in the course of the survey, but not overcoming the threshold of $25 \%$ of the elections: in-house and team training of personnel of educational organizations, information and methodological centers and services in the field of innovation; carrying out organizational and activity games; solution of cases; Singaporean teaching methods.

\section{DISCUSSION}

The data obtained in the study indicate that innovative activity in the regional educational system can rightfully be attributed to complex ecosystems. For the sustainable functioning and development of such an ecosystem, it is necessary to implement a set of measures of a motivational, informational, educational, managerial and organizational nature, which would make it possible to remove individual contradictions, ensure the stability of information exchange processes, and attract additional resources.

The conditionality of the effectiveness of individual managerial and pedagogical practices of stimulating and implementing the innovative activity of subjects of the educational process by the processes and factors of management is due to:

- the special role of management in ensuring the sustainability of the educational system, the balance between its current functioning and development;

- significant influence of management on the distribution and consumption of all types of resources in the education system, especially in the context of the implementation of intensive innovative practices;

- expanding the space of innovative education by including a number of other spaces and environments in its structure, integrating them within a single cross-multidimensional phenomenon.

\section{CONCLUSION}

In conclusion, it should be noted that the problem of innovation ecosystems of regional education, on the one hand, is not new. A sufficient number of publications are devoted to the study of the management of innovation activities at the regional and municipal levels. At the same time, the introduction into the analyzed and studied object of a position associated with cross-multidimensional spaces and environments, causes the appearance of fundamentally different properties and characteristics of this object. This, logically, requires the use of a new apparatus and research methodology.

The results of the study are expressed in the empirical establishment of a complex of factors that determine the degree and effectiveness of the participation of teachers in innovative activities. These results are also expressed in the identification of effective management and pedagogical practices for stimulating and implementing the innovative activity of the subjects of the educational process. At the same time, the results obtained in the course of the research emphasize the importance of management itself and management mechanisms in ensuring the balance of the innovation ecosystem of regional education.

The practical significance of the study lies in the possibility of using its results in the development of innovative models and mechanisms for their 
implementation at various organizational levels, especially taking into account the crossmultidimensional specifics of educational activities, including the choice of the optimal scheme for combining personality-oriented, activity-oriented and environment-oriented pedagogical technologies.

Prospects for further research within the framework of the stated problem may be related to the issues of tiered construction of the ecosystem of innovative education in the region, routing of information flows, variability of crossmultidimensional models of educational activity, minimization of the risks of dehumanization of the educational environment.

\section{AUTHORS' CONTRIBUTIONS}

The writing of the article was made possible thanks to the efforts and contributions of each of the authors. Tatyana G. Ryboretskaya analyzed and summarized numerous innovative practices in the regional education system, took an active part in identifying the factors that hinder the participation of teachers in innovative activities, limiting their innovative activity. Kseniya A. Elistratova introduced the idea of cross-multidimensional spaces and environments into the research methodology, extrapolated a multi-media approach to the problems of the innovative system of regional education. Irina A. Donina carried out work on the analysis and justification of the possibility of using the ecosystem approach in relation to the issues of innovation in the regional education system.

\section{REFERENCES}

[1] R. Kapur, V. Byfield, F. Del Frate, M. Higgins, S. Jagannathan, "The Digital Transformation of Education", Earth Observation Open Science and Innovation, 2018, vol. 15, pp. 25-41. DOI: 10.1007/978-3-319-65633-5_2

[2] N.E. Serditova, A.V. Belotserkovsky, "Education, Quality and the Digital Transformation", Higher Education in Russia, 2020, vol. 4, pp. 9-15. (In Russ.). DOI: 10.31992/0869-3617-2020-29-4-9-15
[3] M.A.M. Hashim, I. Tlemsani, R. Matthews, "Higher education strategy in digital transformation", Education and Information Technologies, 2021, Sep. 14, pp. 1-25. DOI: 10.1007/s10639-021-10739-1

[4] P.V. Tereliansky, N.V. Kuznetsov, K.V. Ekimova, S.A. Lukyanov, "Transformation of education in the digital age", University Management: Practice and Analysis, 2018, vol. 6, pp. 36-43. (In Russ.). DOI: 10.15826/UMPA.2018.06.056

[5] E.V. Pogorelova, T.B. Efimova, "Digital Transformation of Education, Science and Innovations", Lecture Notes in Networks and Systems, 2020, vol. 84, pp. 54-61. DOI: 10.1007/978-3-030-27015-5_7

[6] Decree of the President of the Russian Federation of May 7, 2018 No. 204 "On National Goals and Strategic Objectives for the Development of the Russian Federation for the Period up to 2024”. (In Russ.).

[7] Decree of the President of the Russian Federation of July 21, 2020 "On the National Development Goals of the Russian Federation for the Period up to 2030". (In Russ.).

[8] E.V. Shkarupeta, D.N. Bachurin, "Conceptual provisions of the ecosystem approach to managing the development of economic systems in the context of digital transformation", Organizer of Production, 2020, vol. 28(3), pp. 715. (In Russ.). DOI: 10.25987/VSTU.2020.32.34.001

[9] B.V. Oleynikov, S.A. Podlesny, "On the Conception of «Learning Ecosystem» and Development Directions of Education Informatization", Knowledge. Understanding. Skill, 2013, vol. 4, pp. 84-91. (In Russ.).

[10]Learning Ecosystem for Higher Education Disruption: A New Approach Proposal Based on Blended Active Learning Techniques, 2018. Retrieved from: https://www.researchgate.net/ publication/326305123_Learning_Ecosystem_F or_Higher_Education_Disruption_A_New_App roach_Proposal_Based_On_Blended_Active_Le arning_Techniques 